\title{
Clinical significance of MCP-1 levels in BALF and serum in patients with interstitial lung diseases
}

\author{
M. Suga, K. Iyonaga, H. Ichiyasu, N. Saita, H. Yamasaki, M. Ando
}

\begin{abstract}
Clinical significance of $M C P-1$ levels in BALF and serum in patients with interstitial lung diseases. M. Suga, K. Iyonaga, H. Ichiyasu, N. Saita, H. Yamasaki, M. Ando. (C)ERS Journals Ltd 1999.

ABSTRACT: It has previously been reported that the expression of monocyte chemoattractant protein-1 (MCP-1) in the lung tissues of patients with idiopathic pulmonary fibrosis (IPF) was different from that in the tissues of patients with other interstitial lung diseases (ILDs). The aim of this study was to determine whether this difference reflects the amount of MCP-1 in the bronchoalveolar lavage fluid (BALF) or serum of patients with ILD, and whether such a correlation, if it exists, is clinically useful.

MCP-1 concentrations in the BALF and sera were evaluated in 86 patients with ILDs including IPF, acute interstitial pneumonia, interstitial pneumonia with collagen vascular disease (IP-CVD), chronic interstitial pneumonia (CIP), bronchiolitis obliterans-organizing pneumonia, sarcoidosis, hypersensitivity pneumonitis, and in $\mathbf{1 0}$ normal healthy volunteers who were controls (NC).

BALF MCP-1 levels were significantly elevated in the IPF, IP-CVD, CIP and sarcoidosis groups compared with the NC group. The level in the IPF group was significantly higher than that in any other patient group. Serum MCP-1 levels in the IPF, IP-CVD, CIP and sarcoidosis groups were significantly higher than the NC group. No statistical difference was found in serum MCP-1 levels between the IPF, IP-CVD and CIP groups. BALF MCP-1 levels were significantly higher than serum MCP-1 levels in the IPF group and lower than in the IP-CVD and CIP groups. Serum MCP-1 levels correlated with the clinical course of ILD treated with corticosteroid therapy.

These results show that measurement of monocyte chemoattractant protein-1 levels in both bronchoalveolar lavage fluid and serum may be helpful in discriminating idiopathic pulmonary fibrosis from other types of interstitial lung disease and that monitoring of serum monocyte chemoattractant protein-1 may be useful for predicting the clinical course of interstitial lung diseases.

Eur Respir J 1999; 14: 376-382.
\end{abstract}

\author{
First Dept of Internal Medicine Kuma- \\ moto University School of Medicine, \\ Honjo 1-1-1, Kumamoto 860-0811, Japan \\ Correspondence: M. Suga \\ First Dept of Internal Medicine \\ Kumamoto University School of Medicine \\ 1-1-1 Honjo \\ Kumamoto 860-0811 \\ Japan \\ Fax: 81963710582
}

Keywords: Idiopathic pulmonary fibrosis interstitial lung disease

monocyte chemoattractant protein-1

Received: May 61998

Accepted after revision March 301999
Monocyte chemoattractant protein-1 (MCP-1) belongs to the $\mathrm{C}-\mathrm{C}$ subfamily of the chemokine family, and has been shown to have monocyte chemotactic activity both in vitro and in vivo [1-3]. In pulmonary inflammation models [4,5] and human interstitial lung diseases (ILDs) $[6,7]$, MCP-1 appears to be an important factor in the monocyte/macrophage-mediated inflammatory process. ANTONIADES et al. [7] reported that epithelial cells, macrophages and vascular endothelial cells are the major MCP-1-producing cells in idiopathic pulmonary fibrosis (IPF) lung tissue. MCP-1 has previously been detected immunohistochemically in metaplastic epithelial cells, alveolar and interstitial macrophages and vascular endothelial cells in IPF lung tissues [8]. In other kinds of ILD, MCP-1 was not detected in epithelial cells, although macrophages and vascular endothelial cells were similarly labelled with antiMCP-1 [8]. Given previous findings, differences in the amount of MCP-1 in bronchoalveolar lavage (BAL) fluid (BALF) or serum between IPF and other ILDs were expected. Recently, elevation of MCP-1 concentration and monocyte chemotactic activity in BALF from patients with IPF and sarcoidosis was reported [6]. However, the MCP-1 concentration in BALF from other ILDs, the relation between MCP-1 in BALF and sera, and how changes in serum MCP-1 levels reflect the clinical course of ILD are still unclear.
In the present study, with the aim of determining the clinical significance of MCP-1 levels for discriminating IPF from other ILD and of considering whether MCP-1 is a valuable serum marker in ILD, MCP-1 concentrations in both BALF and sera from patients with several kinds of ILD, including IPF, were measured using an MCP-1specific enzyme-linked immunosorbent assay (ELISA).

\section{Materials and methods}

\section{Study population}

The study population consisted of 86 patients with ILD (27 smokers, 60 nonsmokers) and 10 normal healthy volunteer controls (NC, five smokers, five nonsmokers) for comparison. BAL was not performed in five patients with acute interstitial pneumonia (AIP) due to severe respiratory failure. None of the patients had received corticosteroids or other immunosuppressive therapies until the beginning of this study. Since no difference in the BALF or serum MCP1 levels was observed between smokers and nonsmokers in all groups including normal volunteers, no distinction was made and all subjects were analysed together. All of the subjects gave appropriate informed consent to this study. The study design was approved by the institutional ethical committee. 
The IPF group (15 males, six females; 10 smokers, 11 nonsmokers; mean age 63.8 yrs, range $37-74$ yrs) was diagnosed by means of established criteria, including open lung biopsy $[9,10]$. All were pathologically proven to have usual interstitial pneumonia. The AIP group (two males, three females; two smokers, three nonsmokers; mean age 54.8 yrs, range $42-69$ yrs) was clinically diagnosed by excluding other diseases. It was not possible to measure MCP-1 concentrations in BALF in this group. The group with interstitial pneumonia due to collagen vascular disease (IP-CVD; four males, 15 females; five smokers, 14 nonsmokers; mean age 52.7 yrs, range 22-74 yrs) consisted of four patients with rheumatoid arthritis, five with progressive systemic sclerosis, two with polyarteritis nodosa, two with Sjögren's disease, five with polymyositis and one with mixed connective tissue disease. Although the lung involvement of one patient with rheumatoid arthritis and one with polyarteritis nodosa were diagnosed by open lung biopsy, other IP-CVD patients were diagnosed by transbronchial lung biopsy and radiological features [10-14]. The chronic interstitial pneumonia not otherwise specified (CIP) group (three males, 10 females; three smokers, 10 nonsmokers; mean age 62.5 yrs, range 45-70 yrs) was diagnosed via open lung biopsy based on previously described criteria [10]. The bronchiolitis obliterans-organizing pneumonia (BOOP) group (five males, two females; three smokers; four nonsmokers; mean age 52.0 yrs, range 44-72 yrs) was also diagnosed by means of established criteria utilizing open lung biopsy [10]. In the group of sarcoidosis (four males and 12 females; three smokers, 13 nonsmokers; mean age $41.0 \mathrm{yrs}$, range $28-70 \mathrm{yrs}$ ) diagnosis was made on the basis of established criteria including transbronchial lung biopsy [10, 15]. Radiologically, all cases showed lung infiltration. The Japanese summer-type hypersensitivity pneumonitis (HP) group (five females; five nonsmokers; mean age 52.0 yrs, range 46-68 yrs) was diagnosed using the criteria established in the author's laboratory [16].

\section{Bronchoalveolar lavage}

BAL was performed under local anaesthesia with $2 \%$ lidocaine. A fibreoptic bronchoscope was gently wedged into the segmental bronchus of the middle lobe of the right lung. A total of $150 \mathrm{~mL}$ sterile $0.9 \%$ saline was instilled in 3 aliquots and recovered by gentle hand suction. Mucus was removed from the fluid by filtration through two sheets of gauze. Lavage fluid was centrifuged for $10 \mathrm{~min}$ at
$400 \times g$ at $4{ }^{\circ} \mathrm{C}$ to separate cells and cell-free fluid. The cellfree lavage fluid was stored at $-80^{\circ} \mathrm{C}$ until further analysis. Subsequent measurements of MCP-1 levels demonstrated no decrease in concentration. However, since repeated freezing and thawing may lead to loss of MCP-1 biological activity, these procedures were avoided. The number of cells in the BALF was then determined using a haemocytometer. Cell differentials were determined via Giemsa staining of 200 cells prepared by cytocentrifugation (Cytospin-2; Shandon Instruments, Sewickley, PA, USA). Cell numbers and differentials were expressed as mean \pm SEM. A serum sample was also collected from each subject and stored at $-80^{\circ} \mathrm{C}$ on the same day.

Because repeated invasive procedures were deliberately not included in this study, sequential BAL was not performed.

\section{Quantification of monocyte chemoattractant protein-1 levels in bronchoalveolar lavage fluid and serum}

The MCP-1 level in BALF and serum was measured by means of a sandwich ELISA, as previously described [17]. A well-characterized anti-human MCP-1 mouse monoclonal antibody (MAb) and an anti-human rabbit polyclonal antibody were employed [17]. Briefly, a microtitre plate (Nunc, Roskilde, Denmark) was coated with anti-MCP-1 MAb (clone E11) in coating buffer $\left(0.015 \mathrm{M} \mathrm{Na}_{2} \mathrm{CO}_{3}\right.$, $0.035 \mathrm{M} \mathrm{NaHCO}, 0.003 \mathrm{M} \mathrm{NaN}_{3}, \mathrm{pH}$ 9.6) overnight at $4{ }^{\circ} \mathrm{C}$. After the well contents were removed, $300 \mu \mathrm{L} 0.2 \%$ bovine serum albumin (Sigma, St. Louis, MO, USA) in coating buffer was added and the plate incubated for 30 min at $37^{\circ} \mathrm{C}$. Recombinant human MCP-1 (rhMCP-1, Peprotec, Rocky Hill, NJ, USA) at concentrations ranging $10-20,000 \mathrm{pg} \cdot \mathrm{mL}^{-1}$ and serial dilutions of samples in a final volume of $100 \mu \mathrm{L}$ washing buffer $(0.05 \mathrm{M}$ tris (hydroxymethyl) aminomethane (Tris) base, $0.15 \mathrm{M} \mathrm{NaCl}$, $0.05 \%$ Tween $20, \mathrm{pH} 7.5$ ) were then applied. The plate was incubated for $90 \mathrm{~min}$ at $37^{\circ} \mathrm{C}$. After washing the wells three times with $200 \mu \mathrm{L}$ washing buffer, $100 \mu \mathrm{L}$ antiMCP-1 polyclonal immunoglobulin G diluted 1:1000 in washing buffer was added, and the plate was incubated for $90 \mathrm{~min}$ at $37^{\circ} \mathrm{C}$. After washing, $100 \mu \mathrm{L}$ peroxidaseconjugated donkey anti-rabbit immunoglobulins $\left(\mathrm{F}\left(\mathrm{ab}^{\prime}\right)_{2}\right)$ (Amersham, Amersham, UK) diluted 1:1000 in the washing buffer were added and the plate was incubated for 60 min at room temperature. The wells were washed three times with $0.05 \mathrm{M}$ Tris-buffered saline, allowed to react with $100 \mu \mathrm{L}$ of $2,2^{\prime}$-azinobis (3'-ethylbenzthiazoline)

Table 1. - General characteristics of BALF in patients with interstitial lung diseases*

\begin{tabular}{lcccccc}
\hline & $\begin{array}{c}\text { Patients } \\
\mathrm{n}\end{array}$ & $\begin{array}{c}\text { Total cells } \\
\times 10^{4} \text { cells } \cdot \mathrm{mL}^{-1}\end{array}$ & $\begin{array}{c}\text { Total AMs } \\
\times 10^{4} \text { cells } \cdot \mathrm{mL}^{-1}\end{array}$ & AMs & Lyms & PMNs \\
\cline { 5 - 7 } & 21 & $20.5 \pm 2.1^{*}$ & $16.5 \pm 2.4^{*}$ & $81.8 \pm 3.5$ & $8.9 \pm 2.6$ & $7.3 \pm 2.2$ \\
IPF & 19 & $25.1 \pm 2.9^{*}$ & $17.8 \pm 3.4^{*}$ & $68.8 \pm 4.8$ & $23.3 \pm 4.3$ & $7.4 \pm 3.1$ \\
IP-CVD & 13 & $23.7 \pm 3.3^{*}$ & $18.5 \pm 5.1^{*}$ & $60.7 \pm 6.8$ & $31.8 \pm 5.3^{*}$ & $6.9 \pm 2.1$ \\
CIP & 7 & $34.3 \pm 6.2^{*}$ & $14.5 \pm 2.7^{*}$ & $44.9 \pm 4.1^{*}$ & $43.5 \pm 2.0^{*}$ & $7.5 \pm 1.4$ \\
BOOP & 16 & $32.4 \pm 5.9^{*}$ & $15.0 \pm 1.6^{*}$ & $68.2 \pm 4.1^{*}$ & $30.1 \pm 3.9^{*}$ & $1.4 \pm 0.5^{*}$ \\
Sar & 5 & $82.0 \pm 31.8^{*}$ & $16.9 \pm 4.3^{*}$ & $27.5 \pm 8.6^{*}$ & $71.5 \pm 9.8^{*}$ & $0.9 \pm 0.7$ \\
HP & 10 & $9.9 \pm 0.6$ & $8.9 \pm 0.5$ & $90.4 \pm 1.8$ & $8.1 \pm 1.5$ & $1.4 \pm 0.7$ \\
NC & & &
\end{tabular}

Data are presented as mean \pm SEM. AMs: alveolar macrophages; Lyms: lymphocytes; PMNs: polymorphonuclear cells IPF: idiopathic pulmonary fibrosis; IP-CVD: interstitial pneumonia due to collagen vascular disease; CIP: chronic interstitial pneumonia not otherwise specified; BOOP; bronchiolitis obliterans-organizing pneumonia; Sar: sarcoidosis; HP: Japanese summer-type hypersensitivity pneumonitis; NC: normal healthy volunteer control. *: $\mathrm{p}<0.05$ versus $\mathrm{NC}$. 
sulphonic acid (KPL Inc., Gaithersburg, MD, USA) and then read spectrophotometrically at $405 \mathrm{~nm}$. The sensitivity limit of the assay was $78 \mathrm{pg} \cdot \mathrm{mL}^{-1}$. Data for different groups were presented as means \pm SEM.

\section{Statistical analysis}

BALF analysis data and MCP-1 levels are reported as mean \pm SEM. Comparisons between patient groups were made using the nonparametric Mann-Whitney U-test, since the data do not approximate to a normal distribution. Pearson correlation coefficients and associated tests were also performed for all groups. Differences were considered statistically significant at a p-value $<0.05$.

\section{Results}

\section{General characterization of $B A L F$}

The BALF components of all groups are shown in table 1. All patient groups showed a significantly higher total cell count and alveolar macrophage count than did the NC group $(\mathrm{p}<0.05)$. The mean percentage of lymphocytes was significantly higher in IP-CVD, CIP, BOOP, sarcoidosis and $\mathrm{HP}$ than in $\mathrm{NC}$, whereas the mean percentage of alveolar macrophages was significantly lower in BOOP, sarcoidosis, and HP than in NC $(\mathrm{p}<0.05)$.

\section{Monocyte chemoattractant protein-1 levels in broncho- alveolar lavage fluid}

MCP-1 levels in BALF were measured by means of ELISA in the 91 study subjects listed in table 1 . These levels were below the detection limit $\left(<78 \mathrm{pg} \cdot \mathrm{mL}^{-1}\right)$, i.e. not detectable in all NC subjects; however, in 65 patients, a significant amount was detected. In all 21 IPF patients, 15 of 19 IP-CVD patients, nine of 13 CIP patients, five of seven BOOP patients, 14 of 16 sarcoidosis patients, and one of five HP patients, MCP-1 was detected in BALF.

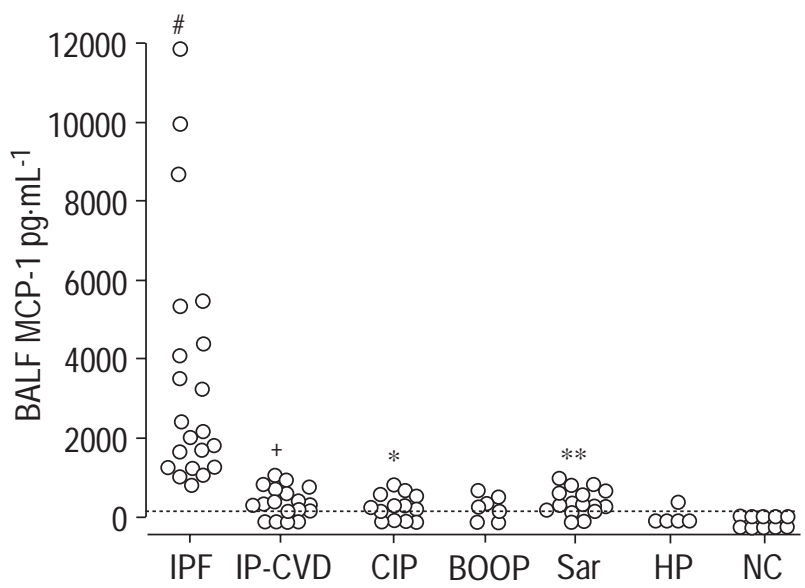

Fig. 1. - Bronchoalveolar lavage fluid (BALF) monocyte chemoattractant protein-1 (MCP-1) concentrations measured by means of specific enzyme-linked immunosorbent assay. MCP-1 in BALF was detected in 65 patients of 91 study subjects. $\cdots \cdots \cdots$. detection limit $(78 \mathrm{pg} \cdot \mathrm{mL}$ $\mathrm{BALF}^{-1}$ ). IPF: idiopathic pulmonary fibrosis; IP-CVD: interstitial pneumonia due to collagen vascular disease; CIP: chronic interstitial pneumonia not otherwise specified; BOOP: bronchiolitis obliterans-organizing pneumonia; Sar: sarcoidosis; HP: Japanese summer-type hypersensitivity pneumonitis; NC: normal healthy control volunteer. ${ }^{*}{ }^{* *},{ }^{*}: \mathrm{p}<0.05 ; \mathrm{p}<$ $0.01, \mathrm{p}<0.005$, respectively versus $\mathrm{NC} ;{ }^{\#}: \mathrm{p}<0.0001$ versus all other group.

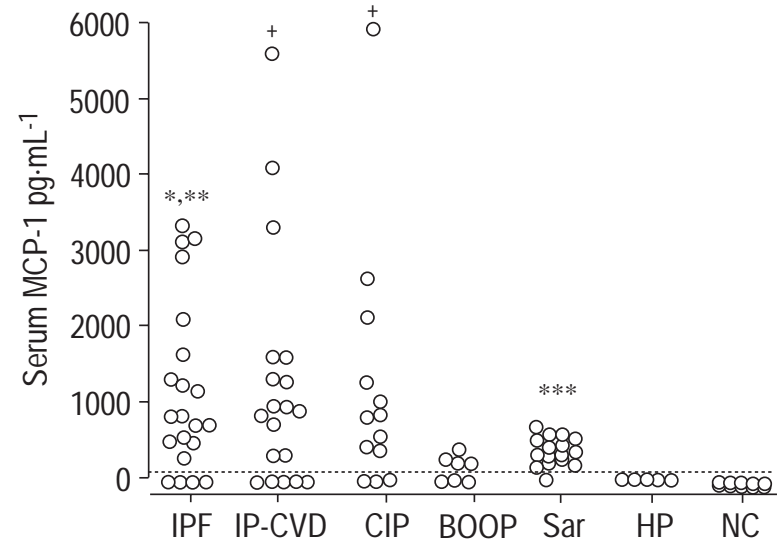

Fig. 2. - Serum monocyte chemoattractant protein-1 (MCP-1) concentrations measured by means of specific enzyme-linked immunosorbent assay. MCP-1 in serum was detected in 60 patients of 91 study subjects. detection limit $\left(78 \mathrm{pg} \cdot \mathrm{mL} \mathrm{BALF}^{-1}\right)$. IPF: idiopathic pulmonary fibrosis; IP-CVD: interstitial pneumonia due to collagen vascular disease; CIP: chronic interstitial pneumonia not otherwise specified; BOOP: bronchiolitis obliterans-organizing pneumonia; Sar: sarcoidosis; HP: Japanese summer-type hypersensitivity pneumonitis; $\mathrm{NC}$ : normal healthy control volunteer. ${ }^{*}: \mathrm{p}<0.01$ versus $\mathrm{BOOP}, \mathrm{Sar}, \mathrm{HP} ;{ }^{+}, * * * * *$ : $\mathrm{p}<0.01$; $\mathrm{p}<0.005, \mathrm{p}<0.001$ respectively versus $\mathrm{NC}$.

Figure 1 is a scatter plot of the level in each sample. The levels were significantly higher in IPF $(\mathrm{p}<0.0001)$, IPCVD $(p<0.005)$, CIP $(p<0.05)$ and sarcoidosis $(p<0.01)$ groups than in the NC group. Especially in the IPF group, all samples showed very high concentrations. The IPF group also showed significantly higher levels of BALF MCP-1 than any other patient group, including IP-CVD and sarcoidosis $(\mathrm{p}<0.0001)$.

\section{Monocyte chemoattractant protein-1 levels in serum}

A significant serum MCP-1 concentration was detected in 60 of 91 study subjects. Figure 2 is a scatter plot of the concentration in each sample. Levels were below the detection limit $\left(<78 \mathrm{pg} \cdot \mathrm{mL}^{-1}\right)$ in all members of the $\mathrm{NC}$ group and all five HP patients. Levels were elevated in 17 of 21 IPF patients, 14 of 19 IP-CVD patients, 10 of 13

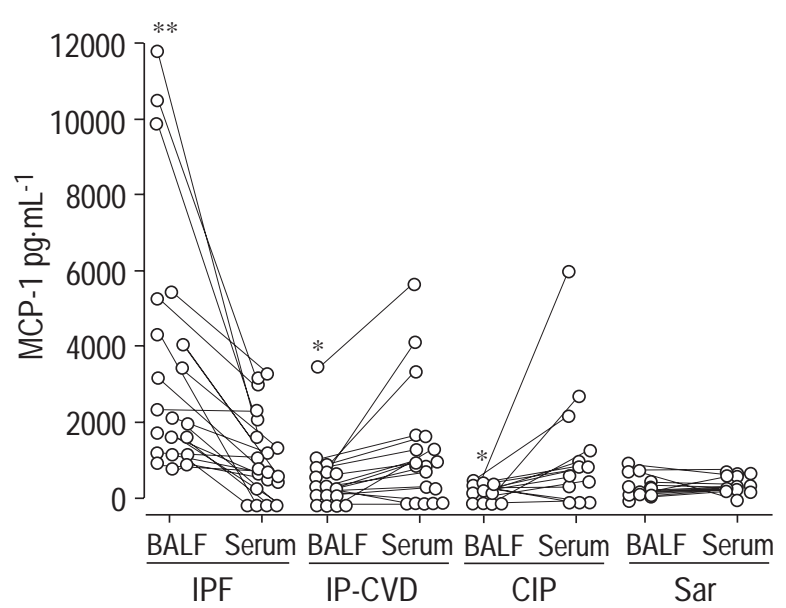

Fig. 3. - Relationship between bronchoalveolar lavage fluid (BALF) and serum monocyte chemoattractant protein-1 (MCP-1) levels in each study subject. IPF: idiopathic pulmonary fibrosis; IP-CVD: interstitial pneumonia due to collagen vascular disease; CIP: chronic interstitial pneumonia not otherwise specified; Sar: sarcoidosis. ***: $\mathrm{p}<0.05$, $\mathrm{p}<0.01$ respectively versus serum levels. 
CIP patients and 15 of 16 sarcoidosis patients. Levels in the IPF, IP-CVD, CIP and sarcoidosis groups were significantly higher than those in the NC and HP groups. No statistically significant difference was observed between the IPF, IP-CVD, CIP and sarcoidosis groups.

The relation between BALF and serum MCP-1 levels of each subject is depicted in figure 3. BALF levels were significantly higher than serum levels in the IPF group $(p<0.01)$ and were significantly lower in the IP-CVD and CIP groups $(\mathrm{p}<0.05)$. In the sarcoidosis group, the ele- vation of BALF MCP-1 was consistent with that of serum MCP-1. No significant correlation between MCP-1 levels in BALF or serum and total macrophage numbers in BALF was observed in any patient group.

Successive measurements of serum monocyte chemoattractant protein-1 level and clinical course

Serum MCP-1 levels before and after corticosteroid therapy were compared with the patients' clinical data (lactate

Table 2. - Serum monocyte chemoattractant protein-1 (MCP-1) levels before and after corticosteroid therapy compared with clinical data

\begin{tabular}{|c|c|c|c|c|c|c|c|c|}
\hline & $\begin{array}{l}\text { Patient } \\
\text { No. }\end{array}$ & $\begin{array}{l}\text { Corticosteroid } \\
\text { therapy }\end{array}$ & $\begin{array}{l}\mathrm{MCP}-1 \\
\mathrm{pg} \cdot \mathrm{mg}^{-1}\end{array}$ & $\begin{array}{c}\text { LDH } \\
\text { IU }\end{array}$ & $\begin{array}{c}\mathrm{CRP} \\
\mathrm{mg} \cdot \mathrm{dL}^{-1}\end{array}$ & $\begin{array}{c}\text { ESR } \\
\mathrm{mm}\end{array}$ & $\begin{array}{l}\mathrm{VC} \\
\mathrm{L}\end{array}$ & $\begin{array}{l}{\mathrm{Pa}, \mathrm{O}_{2}}^{*} \\
\mathrm{mmHg}\end{array}$ \\
\hline \multirow[t]{16}{*}{ IP-CVD } & \multirow[t]{2}{*}{1} & Before & 5,070 & 825 & 1.12 & 98 & 1.01 & 53.9 \\
\hline & & After & 1,640 & 481 & 0.25 & 46 & 1.09 & 78.9 \\
\hline & \multirow[t]{2}{*}{2} & Before & 3,870 & 355 & 0.77 & 22 & 1.88 & 89.0 \\
\hline & & After & 633 & 485 & 0.25 & 18 & 1.96 & 88.0 \\
\hline & \multirow[t]{2}{*}{3} & Before & 2,392 & 416 & 20.54 & 132 & 2.00 & 50.8 \\
\hline & & After & 1,132 & 369 & 0.56 & 30 & 1.78 & 77.1 \\
\hline & \multirow[t]{2}{*}{4} & Before & 2,180 & 847 & 3.60 & 38 & 1.44 & 78.9 \\
\hline & & After & 560 & 412 & 0.25 & 14 & 1.86 & 84.5 \\
\hline & \multirow[t]{2}{*}{5} & Before & 1,290 & 640 & 6.40 & 64 & 1.96 & 84.5 \\
\hline & & After & 146 & 392 & 0.97 & 18 & 2.10 & 87.8 \\
\hline & \multirow[t]{2}{*}{6} & Before & 909 & 1,222 & 0.65 & 36 & 2.81 & 86.6 \\
\hline & & After & 130 & 477 & 0.25 & 10 & 3.50 & 94.4 \\
\hline & \multirow[t]{2}{*}{7} & Before & 446 & 573 & 3.36 & 35 & 1.31 & 83.2 \\
\hline & & After & 92 & 319 & 0.21 & 11 & 1.57 & 81.7 \\
\hline & \multirow[t]{2}{*}{8} & Before & 900 & 420 & 0.36 & 28 & 2.26 & 78.0 \\
\hline & & After & 3,650 & 876 & 11.2 & 36 & - & $-\$$ \\
\hline \multirow[t]{12}{*}{ CIP } & \multirow[t]{2}{*}{1} & Before & 5,910 & 858 & 3.67 & 75 & 1.52 & 69.2 \\
\hline & & After & 995 & 426 & 0.29 & 16 & 2.11 & 88.2 \\
\hline & \multirow[t]{2}{*}{2} & Before & 2,720 & 370 & 0.87 & 48 & 1.65 & 65.0 \\
\hline & & After & 290 & 279 & 0.24 & 18 & 1.68 & 68.0 \\
\hline & \multirow[t]{2}{*}{3} & Before & 2,350 & 343 & 0.33 & 54 & 0.96 & 77.6 \\
\hline & & After & 430 & 314 & 0.68 & 12 & 1.22 & 76.2 \\
\hline & \multirow[t]{2}{*}{4} & Before & 1,230 & 564 & 0.23 & 30 & 1.22 & 75.5 \\
\hline & & After & 261 & 523 & 0.25 & 24 & 2.01 & 81.8 \\
\hline & \multirow[t]{2}{*}{5} & Before & 817 & 452 & 0.26 & 62 & 1.96 & 63 \\
\hline & & After & 42 & 396 & 0.26 & 12 & 2.42 & 86 \\
\hline & \multirow[t]{2}{*}{6} & Before & 245 & 456 & 0.36 & 38 & 2.16 & 78.0 \\
\hline & & After & 39 & 365 & 0.26 & 12 & 2.80 & 92.0 \\
\hline \multirow[t]{10}{*}{ IPF } & \multirow[t]{2}{*}{1} & Before & 70 & 728 & 11.60 & - & - & $62.8 / 0.5^{+}$ \\
\hline & & After & 2,970 & 878 & 4.20 & - & - & - \\
\hline & \multirow[t]{2}{*}{2} & Before & 1,320 & 850 & 5.40 & - & - & $70.8 / 3^{\#}$ \\
\hline & & After & 2,390 & 670 & 9.80 & - & - & $-\S$ \\
\hline & \multirow[t]{2}{*}{3} & Before & 1,940 & 940 & 10.20 & - & - & 69.1 \\
\hline & & After & 2,580 & 860 & 4.60 & - & - & $-_{-}^{\S}$ \\
\hline & 4 & Before & 828 & 478 & 1.2 & - & - & 62.0 \\
\hline & & After & 2,090 & 868 & 4.8 & - & - & $-\$$ \\
\hline & 5 & Before & 860 & 362 & 0.3 & - & - & $56.0 / 1.0^{+}$ \\
\hline & & After & 5,012 & 960 & 12.3 & - & - & $-\S$ \\
\hline AIP & 1 & Before & 1,138 & 925 & 9.38 & - & - & $85.3 / 5^{\#}$ \\
\hline & & After & 84 & 373 & 1.58 & - & - & 82.0 \\
\hline & 2 & Before & 297 & 582 & 14.2 & - & - & 55.5 \\
\hline & & After & 9,545 & 1,564 & 1.48 & - & - & $-\S$ \\
\hline & 3 & Before & 1,460 & 847 & 7.40 & - & - & $123.2 / 4^{\#}$ \\
\hline & & After & 2,110 & 1,184 & 1.18 & - & - & $-\$$ \\
\hline & 4 & Before & 2,680 & 865 & 11.2 & - & - & 38.0 \\
\hline & & After & 104 & 420 & 0.3 & - & - & 86.0 \\
\hline & 5 & Before & 2,380 & 940 & 9.8 & - & - & 33.0 \\
\hline & & After & 244 & 462 & 1.2 & - & - & 82.0 \\
\hline
\end{tabular}

*: under room air conditions (without oxygen therapy; ${ }^{+}$: arterial oxygen tension $\left(\mathrm{Pa}_{\mathrm{a}} \mathrm{O}_{2}\right) /$ inspiratory oxygen fraction $\left(F \mathrm{I}, \mathrm{O}_{2}\right)($ with respirator); ${ }^{\#}: P_{\mathrm{a}}, \mathrm{O}_{2} /$ volume of oxygen per minute (oxygen via nasal cannula) $;^{\S}$ : died due to respiratory failure. LDH: lactate dehydrogenase; CRP: C-reactive protein; ESR: erythrocyte sedimentation rate; VC: vital capacity; IP-CVD: interstitial pneumonia due to collagen vascular disease; CIP: chronic interstitial pneumonia not otherwise specified; IPF: idiopathic pulmonary fibrosis; AIP: acute interstitial pneumonia. 

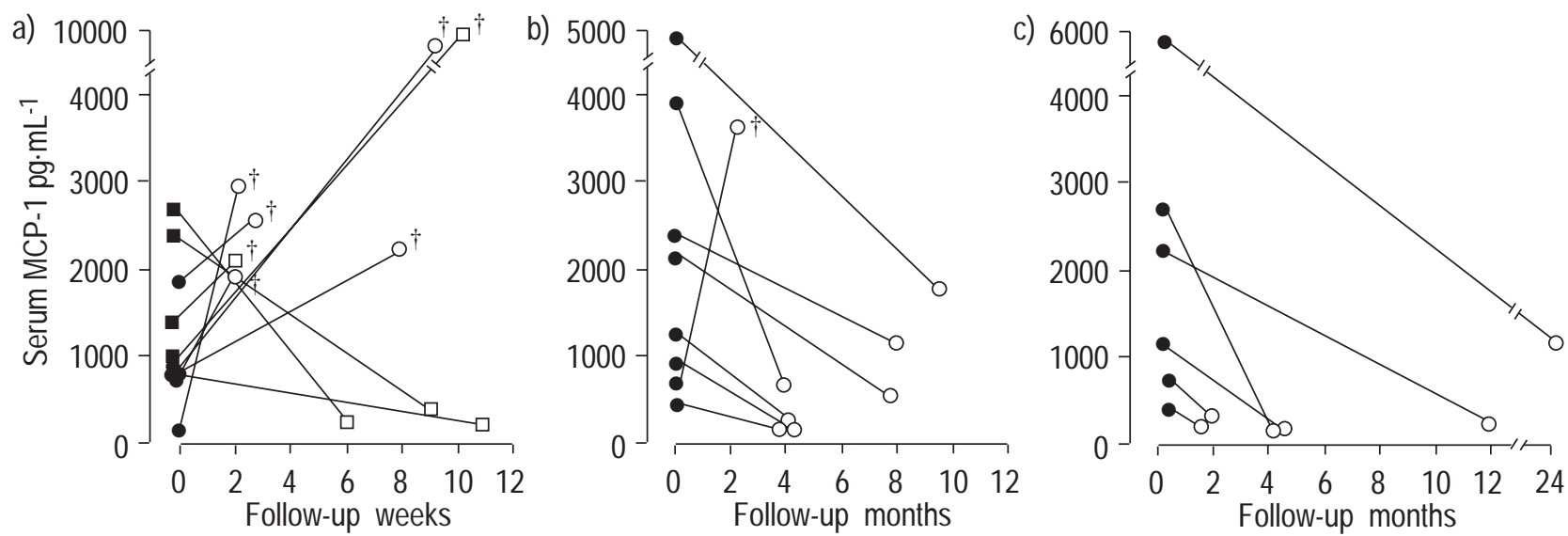

Fig. 4. - Successive measurement of serum monocyte chemoattractant protein-1 (MCP-1) concentrations before $(\mathbf{9})$ and after $(\bigcirc)$ corticosteroid therapy in: a) idiopathic pulmonary fibrosis (IPF) and acute interstitial pneumonia (AIP; $\mathbf{\square}$ : before therapy; $\square$ : after therapy); b) interstitial pneumonia due to collagen vascular disease (IP-CVD); and c) chronic interstitial pneumonia not otherwise specified. Five patients with IPF, two with AIP and one with IP-CVD died (') due to acute exacerbation with concomitant increasing levels of serum MCP-1 despite corticosteroid-pulse therapy (p<0.01).

dehydrogenase $(\mathrm{LDH})$ activity, C-reactive protein $(\mathrm{CRP})$ concentration, erythrocyte sedimentation rate, blood gas analysis and lung function test) in five patients with IPF or AIP, eight with IP-CVD and six with CIP (table 2). Seven patients with IP-CVD and six with CIP who had exhibited progressive dyspnoea with elevation of serum MCP-1 levels were treated with corticosteroid conventionally, and their symptoms improved with a corresponding marked decrease in MCP-1 levels $(p<0.001)$. Chest radiographic findings corresponded markedly to the decrease in serum MCP-1 levels after steroid therapy, with mean follow-up periods of 6.0 months for IP-CVD (range 4-10 months) and of 11.0 months for CIP (range 4-24 months) (fig. 4, table 2). In spite of corticosteroid-pulse therapy, five patients with rapid progression of IPF, two with AIP and one with IP-CVD died because of severe respiratory failure with concomitant increasing levels of serum MCP-
1 (mean follow-up period 22.3 days, range 16-30 days) (fig. 4). Three patients with AIP who showed decreasing serum MCP-1 levels after corticosteroid-pulse therapy were cured (AIP patients 1, 4 and 5 in table 2 and fig. 4). When LDH and CRP levels in serum were compared with MCP-1 levels in patients with IPF and AIP, serum MCP-1 levels correlated well with serum LDH levels. However, when LDH levels increased despite the clinical course of AIP showing improved status, MCP-1 levels decreased following the clinical course of therapy (patient 1, fig. 5). The increased LDH activity was caused by liver dysfunction due to drug-induced hepatitis.

\section{Discussion}

In the present study, the following two findings were demonstrated. 1) The relation between the increases in
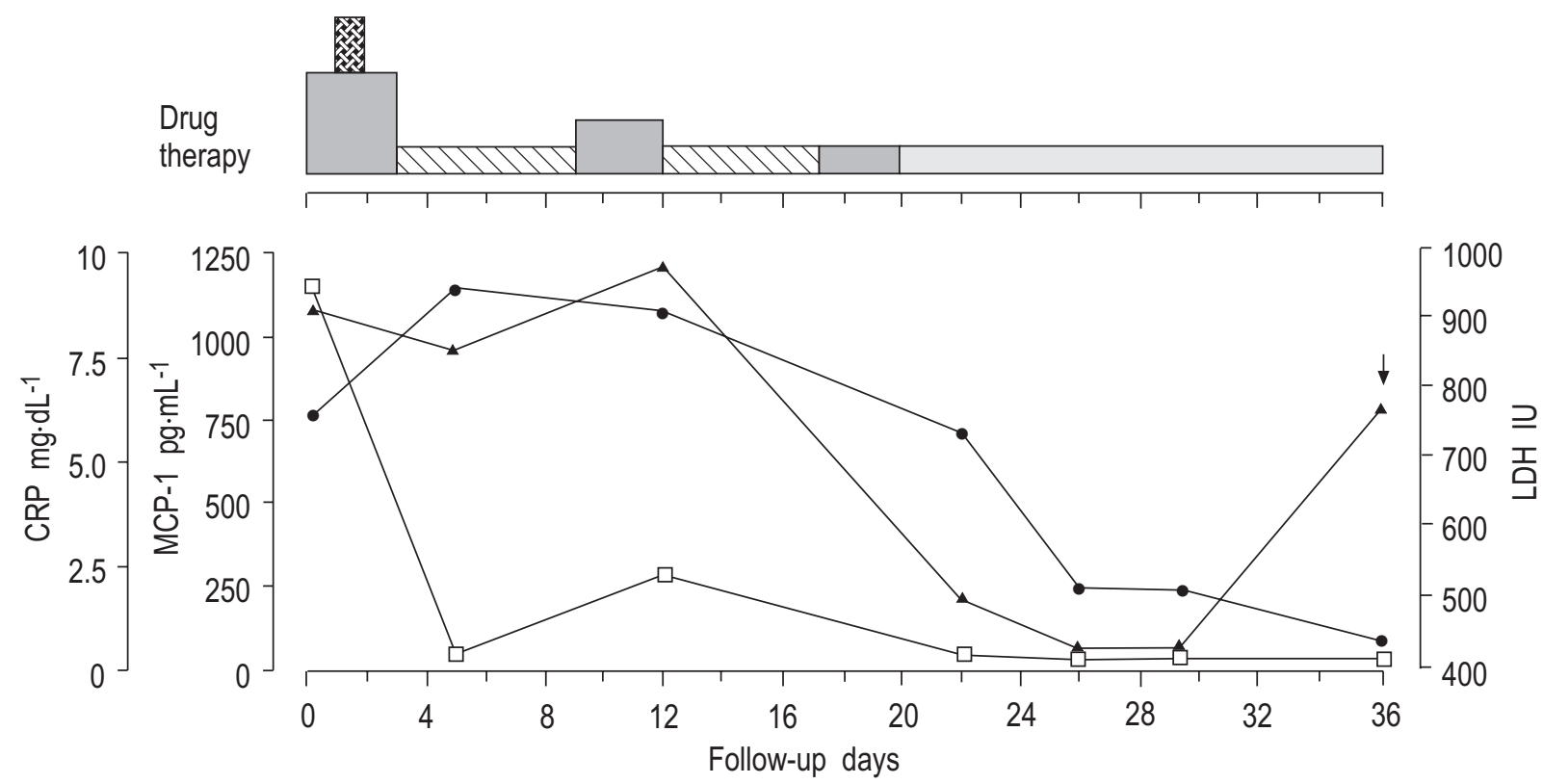

Fig. 5. - Successive measurement of serum monocyte chemoattractant protein-1 (MCP-1, @), C-reactive protein (CRP, $\square$ ) and lactate dehydrogenase $(\mathrm{LDH}, \mathbf{\Delta})$ levels in a patient with acute interstitial pneumonitis (patient 1 in table 1). The patient was alive at the end of follow-up. Drug therapy, cyclophosphomide $500 \mathrm{mg} \cdot \mathrm{day}^{-1}$; $\square$ : methylprednisolone $4 \mathrm{~g} \cdot \mathrm{day}^{-1}$ days $1-3,2 \mathrm{~g} \cdot$ day $^{-1}$ days $9-12$, and $1 \mathrm{~g} \cdot$ day ${ }^{-1}$ days $17-20$; $\mathbb{\$}$ : prednisolone 60 $\mathrm{mg} \cdot \mathrm{day}^{-1} ; \square$ : betamethasone $10 \mathrm{mg} \cdot \mathrm{day}^{-1}$. The arrow indicates increased LDH, which was based on liver dysfunction due to drug induced hepatitis. 
BALF and serum MCP-1 concentrations within each group showed significant differences between IPF and other ILDs. Therefore, these increases may differentiate IPF from other ILDs. 2) Serum MCP-1 levels appeared to correlate with the clinical course of IPF, AIP, IP-CVD and CIP, and were considered a valuable serum marker for estimating the effectiveness of corticosteroid therapy.

The current finding that BALF MCP-1 levels were significantly elevated in patients with IPF, IP-CVD and sarcoidosis is consistent with an earlier report of elevated MCP-1 levels in the BALF from patients with IPF and sarcoidosis [6]. In the present study, the IPF patient group had significantly higher BALF MCP-1 levels than did the IP-CVD and sarcoidosis groups. In addition, BALF MCP1 levels were higher than serum MCP-1 levels for all cases of IPF. These results suggested that the increased MCP-1 was secreted mainly into the airspace in IPF lung tissue and that the presence of MCP-1 in BALF is not merely a reflection of MCP-1 in serum.

Unexpectedly, the number of alveolar macrophages in BALF increased nonspecifically in all patient groups, and there was no significant correlation between MCP-1 concentrations and numbers of alveolar macrophages in the BALF. However, this finding does not make the role of MCP-1 in IPF and other ILDs less important because increased local tissue macrophage replication and prolonged survival of alveolar macrophages in the chronically inflamed lung also have been reported $[18,19]$ and may not be ignored. Many other factors, such as tumour necrosis factor- $\alpha$, transforming growth factor- $\beta$, and regulated on activation, normal T-cell expressed and secreted, that create a local environment at the sites of inflammation may also be involved [20, 21].

A diagnosis of IPF carries a grave prognosis compared to other causes of ILD such as IP-CVD, CIP and chronic HP [9-14, 22]. The differential diagnosis of IPF from other ILDs is sometimes problematic and can contribute to a poor prognosis. In the present study, the significance of the higher BALF than serum MCP-1 levels in the IPF group is important, especially since serum MCP-1 increases were higher than those of BALF MCP-1 in some of the groups. MCP-1 produced in other parts of the body may contribute to the elevation of MCP-1 concentration in sera since collagen vascular disease is a systemic disease usually associated with many complicating disorders in addition to interstitial pneumonia [10-14]. These findings suggest that the differences in the pattern of MCP-1 elevation in BALF and serum may be helpful in the differential diagnosis of IPF from other types of ILD.

In addition to the above findings, the possibility that increases or decreases in serum MCP-1 levels can reflect the clinical improvement or degeneration of patients with IPF, IP-CVD or CIP was demonstrated. IPF usually progresses slowly; however, after a period of slow deterioration, IPF patients often suffer a sudden rapid decline that results in death. An exact evaluation of IPF activity is of enormous value clinically. Chest radiography, lung function tests, blood gas analysis, and determination of serum CRP and LDH levels are usually used during management of this disease. Pulmonary surfactant protein D [23] and KL-6 (a mucin-like glycoprotein) [24-28] have been proposed as new markers for disease activity of ILDs. They correlate well with the serum LDH levels of patients with IPF during the clinical course. LDH is generally accepted as a serum marker of disease activity of ILDs including of IPF. Serum LDH levels correlate well with the clinical course of IPF, but are often influenced by bacterial infection or inflammatory processes affecting other organs. When serum LDH levels were compared with MCP-1 levels in AIP patients and IPF patients with acute exacerbation, serum MCP-1 levels correlated well with LDH. However, when LDH levels were increased by other factors (liver dysfunction and respiratory infection) despite improvement in the clinical course of IPF or AIP, MCP-1 levels decreased. It was confirmed that MCP-1 levels in the serum of patients with respiratory infectious diseases such as pneumonia caused by bacteria did not increase. In this study, when disease progressed to death, serum MCP1 levels increased markedly irrespective of corticosteroid therapy. Seven patients with IPF who exhibited dyspnoea without obvious rapid progression of the disease and who were not receiving therapy showed no significant increase in serum MCP-1 levels in the follow-up periods (mean follow-up period 9.2 months, range 6-12 months) (data not shown). The patients with IP-CVD and CIP with disease progression with increased serum MCP-1 levels were treated with corticosteroids, and they responded to treatment by showing decreased serum MCP-1 levels. Monitoring of serum MCP-1 levels may bring a significant benefit to the treatment of ILDs.

In conclusion, measuring monocyte chemoattractant protein-1 concentrations in both bronchoalveolar lavage fluid and serum may help to discriminate idiopathic pulmonary fibrosis from other types of interstitial lung disease, and monitoring serum monocyte chemoattractant protein-1 levels may enable prediction of the clinical course of interstitial lung disease.

Acknowledgements. The authors thank T. Yoshimura (Laboratory of Immunobiology, National Cancer Institute-Frederick Cancer Research and Development Center, Frederick, MD, USA) for valuable suggestions and reviewing this manuscript.

\section{References}

1. Yoshimura T, Yuhki N, Moore SK, et al. Human monocyte chemoattractant protein-1 (MCP-1). Full length cDNA cloning expression in mitogen stimulated blood mononuclear phagocytes. FEBS Lett 1989; 244: 487-493.

2. Yoshimura T, Robinson EA, Tanaka S, et al. Purification and amino acid analysis of two human monocyte chemoattractant products by phytohaemagglutinin stimulated human blood mononuclear leukocytes. J Immunol 1989; 142: 1956-1962.

3. Rollins BJ, Walz A, Bagiolini M. Recombinant human MCP-1/JE induces chemotaxis, calcium influx, and the respiratory burst in human monocytes. Blood 1991; 78: 1112-1116.

4. Jones ML, Warren JS. Monocyte chemoattractant protein 1 in a rat model of pulmonary granulomatosis. Lab Invest 1992; 66: 498-503.

5. Warren JS, Jones ML, Flory CM. Analysis of monocyte chemoattractant protein 1-mediated lung injury using rat lung organ cultures. Am J Pathol 1993; 143: 894-906.

6. Car BD, Meloni F, Luisetti M, et al. Elevated IL-8 and MCP-1 in bronchoalveolar lavage fluid of patients with idiopathic pulmonary fibrosis and pulmonary sarcoidosis. Am J Respir Crit Care Med 1994; 149: 655-659. 
7. Antoniades HN, Neville-Golden J, Galanopoulos T, et al. Expression of monocyte chemoattractant protein $1 \mathrm{mRNA}$ in human idiopathic pulmonary fibrosis. Proc Natl Acad Sci USA 1992; 89: 5371-5375.

8. Iyonaga $\mathrm{K}$, Takeya M, Saita N, et al. Monocyte chemoattractant protein-1 in idiopathic pulmonary fibrosis and other interstitial lung diseases. Hum Pathol 1994; 25: 455-463.

9. Carrington CB, Gaensler EA, Coutu RE, et al. Natural history and treated course of usual and desquamative interstitial pneumonia. N Engl J Med 1978; 298: 801-809.

10. Katzenstein ALA, Askin FB. Surgical pathology of nonneoplastic lung disease. Major Prob Pathol 1990; 13: 996, 214-289.

11. Yousem SA, Colby TV, Carrington CB. Lung biopsy in rheumatoid arthritis. Am Rev Respir Dis 1985; 131: 770777.

12. Rossi GA, Bitterman PB, Rennard SI, et al. Evidence for chronic inflammation as a component of the interstitial lung disease associated with progressive systemic sclerosis. Am Rev Respir Dis 1985; 131: 612-617.

13. Strimlan CV, Rosenow EC III, Divertie MB, et al. Pulmonary manifestations of Sjogren's syndrome. Chest 1976; 70: 354-361.

14. Wiener-Kronish JP, Solinger AM, Warnock ML, et al. Severe pulmonary involvement in mixed connective tissue disease. Am Rev Respir Dis 1981; 124: 499-503.

15. Thomas PD, Hunninghake GW. Current concepts of the pathogenesis of sarcoidosis. Am Rev Respir Dis 1987; 135: 747-760.

16. Ando M, Arima K, Yoneda R, et al. Japanese summertype hypersensitivity pneumonitis: geographic distribution, home environment, and clinical characteristics of 621 cases. Am Rev Respir Dis 1991; 144: 765-769.

17. Yoshimura T, Takeya M, Takahashi K, et al. Production and characterization of mouse monoclonal antibodies against human monocyte chemoattractant protein-1. J Immunol 1991; 147: 2229-2233.
18. Bitterman PB, Saltzman LE, Adelberg S, et al. Alveolar macrophage replication: one mechanism for the expansion of the mononuclear phagocyte population in the chronically inflamed lung. $J$ Clin Invest 1984; 74: 460-469.

19. Lin S-A, Lokeshwar BL, Hsu S. Both granulocytemacrophage CSF and macrophage CSF control the proliferation and survival of the same subset of alveolar macrophages. J Immunol 1988; 142: 515-519.

20. Wahl SM, Hunt DA, Wakefield LM, et al. Transforming growth factor type $\mathrm{b}$ induces monocyte chemotaxis and growth factor production. Proc Natl Acad Sci USA 1987; 84: 5788-5792.

21. Schall TJ, Bacon K, Toy KJ, et al. Selective attraction of monocytes and T-lymphocytes of the memory phenotype by cytokine RANTES. Nature 1990; 347: 669-671.

22. Katzenstein ALA, Fiorelli RF. Nonspecific interstitial pneumonia/fibrosis: histologic features and clinical significance. Am J Surg Pathol 1994; 18: 136-147.

23. Honda Y, Kuroki Y, Matsuura E, et al. Pulmonary surfactant protein D in sera and bronchoalveolar lavage fluids. Am J Respir Crit Care Med 1995; 152: 1860-1866.

24. Kobayashi J, Kitamura S. Serum KL-6 for the evaluation of active pneumonitis in pulmonary sarcoidosis. Chest 1996; 109: 1276-1282.

25. Kobayashi J, Kitamura S. KL-6: a serum marker for interstitial pneumonia. Chest 1995; 108: 311-315.

26. Kohno N, Awaya Y, Oyama T, et al. KL-6, a mucin-like glycoprotein, in bronchoalveolar lavage fluid from patients with interstitial lung disease. Am Rev Respir Dis 1993 148; 637-642.

27. Hamada H, Kohno N, Akiyama M, Hiwada K. Monitoring of serum KL-6 antigen in a patient with radiation pneumonia. Chest 1992; 101: 858-860.

28. Kohno N, Kyoizumi S, Awaya Y, Fukuhara H, Yamakido M, Akiyama M. New serum indicator of interstitial pneumonitis activity. Sialylated carbohydrate antigen KL6. Chest 1989; 96: 68-73. 